\title{
Professional Athlete Return to Play and Performance After Shoulder Arthroscopy Varies by Sport
}

\author{
Margaret J. Higgins, B.S., Steven DeFroda, M.D., M.Eng., Daniel S. Yang, B.S., \\ Symone M. Brown, M.P.H., and Mary K. Mulcahey, M.D.
}

\begin{abstract}
Purpose: To determine whether differences in return-to-play (RTP) rate and performance-based outcomes exist following shoulder arthroscopy in athletes from the National Football League (NFL), National Basketball League (NBA), Major League Baseball (MLB), and National Hockey League (NHL). Methods: Professional athletes from the NFL, NBA, MLB, and NHL who underwent shoulder arthroscopy between January 1998 and December 2016 were identified through an established review of injury reports and public archives. Sport-specific statistics were collected before and after shoulder arthroscopy for each athlete, providing a performance score. RTP was defined as the first game played postsurgery. Results: Of the 208 professional athletes who met the inclusion criteria, $167(80.3 \%)$ returned to play following shoulder arthroscopy, with MLB players returning at a significantly lower rate than those of other sports $(P<.0001)$. NBA players had significantly shorter recovery times (201 days; $P<.01)$ and MLB players had significantly longer recovery times $(413$ days; $P<.001)$ when compared with athletes in other sports. The mean number of seasons played after shoulder arthroscopy was 3.7, 4.7, 4.8, and 5.8 for MLB, NFL, NHL, and NBA, respectively. NBA players performed worse in their first season postoperative compared with their preoperative performance $(P=.0017)$, but their postoperative season 2 performance returned to their preoperative performance level $(P=.1893)$. Similarly, NHL players performed worse in their postoperative season 1 compared with preoperative performance $(P=.0274)$, but their postoperative season 2 performance improved upon their preinjury performance level $(P=.0861)$. Conclusions: There is a modest RTP rate among professional athletes following shoulder arthroscopy. MLB players have the longest average time to RTP and the shortest postinjury careers following shoulder arthroscopy. However, they demonstrate no significant decline in performance following their injury. Conversely, NBA players had the shortest average time to RTP and the longest post-injury career. Both NBA and NHL athletes experienced a decrease in performance in post-operative season one. Level of Evidence: Level III, retrospective comparative study.
\end{abstract}

$\mathbf{S}^{\mathrm{h}}$ houlder injuries including instability (dislocation or subluxation), labral tears, loose bodies, and rotator cuff tears are commonly encountered in athletes of all skill levels and can have potentially serious effects on athletic performance. In male patients, these types of shoulder pathologies comprise $8.1 \%$ of all athletic injuries and often warrant arthroscopic treatment. ${ }^{1-3}$ While pain relief and improved function are considered positive outcomes of shoulder arthroscopy in the general public, success in professional athletes is

From Department of Orthopaedic Surgery (S.M.B., M.K.M.), Tulane University School of Medicine (M.J.H., S.M.B., M.K.M.), New Orleans, Louisiana, and Department of Orthopaedic Surgery, Brown University School of Medicine, Providence, Rhode Island (S.D., D.S.Y.), U.S.A.

The authors report the following potential conflicts of interest or sources of funding: S.D. reports other from AAOS, outside the submitted work. M.K.M. reports other from AAOS, other from ACSM Translational Journal, other from American Orthopaedic Society for Sports Medicine, personal fees from Arthrex, other from Arthroscopy Association of North America, other from Ortho Info, other from Ruth Jackson Orthopaedic Society, and other from The typically quantified by return to athletic competition, specifically with the goal of returning to preinjury performance level. ${ }^{4,5}$ Successful return to play (RTP) requires engagement in repetitive, high-impact activities that can be difficult for some athletes depending on the degree of shoulder activity involved in the given sport. $^{6}$

Previous studies have reported a discrepancy with respect to RTP and athletic performance following shoulder injury and shoulder surgery for different

\footnotetext{
Forum, outside the submitted work. Full ICMJE author disclosure forms are available for this article online, as supplementary material.

Received April 28, 2020; accepted October 16, 2020.

Address correspondence to Mary K. Mulcahey, M.D., 1430 Tulane Ave., \#8632, New Orleans, LA 70112.E-mail:mmulcahey@tulane.edu

(C) 2020 THE AUTHORS. Published by Elsevier Inc. on behalf of the Arthroscopy Association of North America. This is an open access article under the CC BY-NC-ND license (http://creativecommons.org/licenses/by-nc-nd/4.0/). 2666-061X/20704

https://doi.org/10.1016/j.asmr.2020.10.001
} 
sports. Park et al. ${ }^{7}$ found an $82 \%$ RTP rate in Major League Baseball (MLB) players after Bankart repair, with an average RTP period of 8.4 months. Chalmers et al. ${ }^{8}$ included both major and minor league players in their study and found a 63\% RTP rate in professional baseball players following shoulder surgery. Robins et al. ${ }^{9}$ reported an $84.5 \%$ RTP rate among National Collegiate Athletic Association Division I intercollegiate football players following shoulder stabilization arthroscopy. Namdari et al. ${ }^{10}$ reported performance statistics of MLB pitchers following rotator cuff tear repair and found that they improved gradually over 3 seasons following their surgery, but their performance did not return to preoperative levels.

Among National Football League (NFL) players who experienced a primary shoulder instability event, Okoroha et al. ${ }^{11}$ found that $31 \%(26 / 83)$ were treated operatively and $69 \%(57 / 83)$ were treated nonoperatively. The RTP rate among these NFL players was $92.8 \%$ (77/83), regardless of whether they were treated operatively or nonoperatively. Notably, the time to RTP for athletes treated operatively was a median of 39.3 weeks, whereas the RTP was a median of 2.3 weeks for athletes treated nonoperatively. A similar study reported RTP in National Basketball Association (NBA) players who experienced a primary shoulder instability event, with a $100 \%(50 / 50)$ RTP rate, regardless of whether they were treated operatively or nonoperatively. In this study, players who underwent nonoperative treatment were able to RTP after a mean of 3.6 weeks, whereas players treated operatively RTP after 18.7 weeks. $^{12}$

Abdul-Rassoul et al. ${ }^{13}$ conducted a systematic review of RTP rate and timeline after anterior shoulder stabilization, which included professional, college, high school, competitive, and recreational athletes. The authors concluded that athletes who underwent arthroscopic Bankart repair showed the greatest rate of RTP $(97.5 \%)$, as well as the greatest rate of return to preinjury performance level $(91.5 \%)$. Athletes who had undergone an arthroscopic Latarjet had a 94\% RTP rate and a $69 \%$ rate of return to preinjury performance level. $^{13}$

There is a paucity of data available regarding RTP rate and overall performance in subsequent seasons among professional athletes following shoulder arthroscopy. ${ }^{7-12}$ This information may be useful to identify sport-specific differences in recovery that may help manage athlete expectations and guide sport-specific rehabilitation. The purpose of this study was to determine whether differences in RTP rate and performancebased outcomes exist following shoulder arthroscopy in athletes from the NFL, NBA, MLB, and NHL (National Hockey League). We hypothesized that there would be significant variability in RTP and performance-based outcomes depending on the sport played, with overhead athletes (MLB, NBA) having more difficulty with RTP and worse postoperative performance.

\section{Methods}

\section{Data Collection}

Professional athletes from 4 major sports (NHL, NFL, NBA, and MLB) who underwent shoulder arthroscopy for instability, labral tear, rotator cuff tear, or distal clavicle excision between January 1998 and December 2016 were identified for this study (Table 1). This study did not require institutional review board approval because data were collected from publicly accessible sources (prosportstransactions.com, sports-reference. com). Results were cross-referenced with team press releases, online injury reports, and player profiles to confirm the diagnosis. This method has been validated in previous studies. ${ }^{14-20}$

Players met the inclusion criteria if initial reports of the date and type of surgery were corroborated by at least 2 independent public sources of information. Players with concomitant injuries requiring repair (e.g., elbow surgery, knee surgery, wrist surgery), when identified, were excluded. Athletes with conflicting medical information from different sources, revision shoulder arthroscopy procedures, unclear pathology, or

Table 1. Reported Rationale for Shoulder Arthroscopy

\begin{tabular}{|c|c|c|c|c|c|}
\hline & NHL $(n=37)$ & NFL $(n=8)$ & $\mathrm{NBA}(\mathrm{n}=46)$ & $\operatorname{MLB}(n=116)$ & Total $(\mathrm{n}=207)$ \\
\hline Dislocation & $3(8.1 \%)$ & $0(0.0 \%)$ & $7(15.2 \%)$ & $1(0.9 \%)$ & $11(5.3 \%)$ \\
\hline Labral tear & $11(28.7 \%)$ & $3(38.5 \%)$ & $13(28.3 \%)$ & $48(41.4 \%)$ & $75(36.2 \%)$ \\
\hline Subluxation & $1(2.7 \%)$ & $0(0.0 \%)$ & $2(4.3 \%)$ & $0(0.0 \%)$ & $3(1.4 \%)$ \\
\hline Torn/tendinitis of rotator cuff & $3(8.1 \%)$ & $3(38.5 \%)$ & $5(10.9 \%)$ & $17(14.7 \%)$ & $28(13.5 \%)$ \\
\hline Removal of bursa and bone spur & $0(0.0 \%)$ & $0(0.0 \%)$ & $2(4.3 \%)$ & $0(0.0 \%)$ & $2(1.0 \%)$ \\
\hline Impingement & $0(0.0 \%)$ & $0(0.0 \%)$ & $0(0.0 \%)$ & $1(0.9 \%)$ & $1(0.5 \%)$ \\
\hline Unspecified & $17(45.9 \%)$ & $0(0.0 \%)$ & $14(30.4 \%)$ & $37(31.9 \%)$ & $68(32.9 \%)$ \\
\hline
\end{tabular}

AC, acromioclavicular joint; MLB, Major League Baseball; NBA, National Basketball Association; NFL, National Football League; NHL, National Hockey League. 


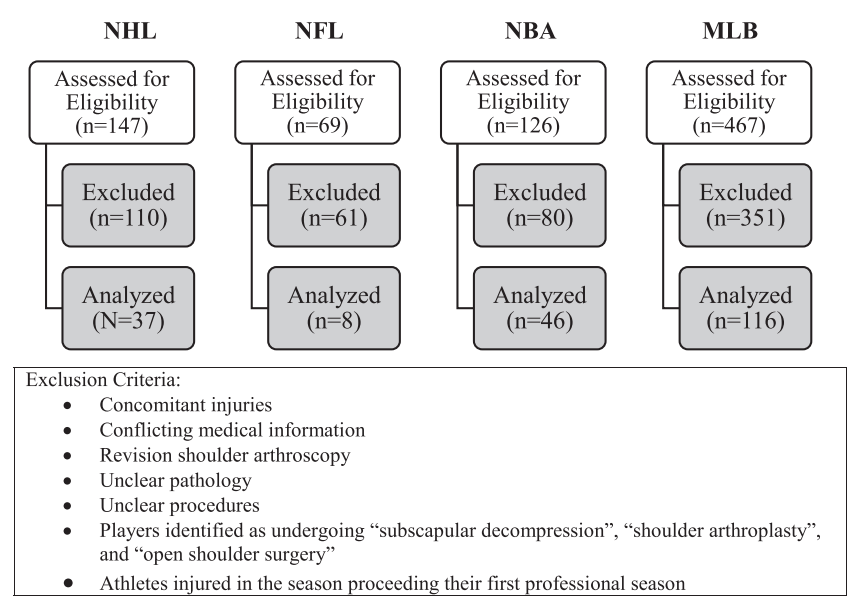

Fig 1. Breakdown of included and excluded arthroscopic shoulder procedures by sport. (MLB, Major League Baseball; NBA, National Basketball Association; NFL, National Football League; NHL, National Hockey League.)

unclear procedures also were excluded. In addition, players identified as undergoing "subscapular decompression." "shoulder arthroplasty." or "open shoulder surgery" were excluded, as were athletes who were injured and underwent shoulder arthroscopy in the season preceding their first professional season. Athletes were assessed for exclusion criteria by the first author (M.J.H).

Demographic data including age, body mass index (BMI), position, years played in their respective professional league, and date of surgery were collected for each player. The number of games and seasons played were compiled both before and after shoulder arthroscopy. RTP date was defined as the date of the first regular or postseason game played in the respective professional league following each arthroscopic shoulder procedure. Statistical performance was calculated differently for each athlete depending on the sport played, using previously published metrics (Appendix 1). ${ }^{15,16,19,21}$ Performance metrics were recorded both pre- and postinjury for each sport to determine the effect of arthroscopic shoulder surgery at both 1 and 2 years postinjury. Different performance metrics were used based on sport (NHL and NFL: an algorithm used in previous literature; NBA: player efficiency rating; and MLB: walks and hits per innings pitched for pitchers, and on-base plus slugging for hitters (Appendix 1). ${ }^{15,19}$

\section{Data Analysis}

To account for differences in season among the 4 sports, a conversion factor was used to standardize data analysis (NHL, 82 games; NFL, 16 games; NBA, 82 games; and MLB, 162 games). Player performance was assessed only for players who returned to play following surgery. Each athlete's baseline performance was defined as the season immediately preceding the injury-shorted season. Postoperative season one was defined as the first season in which the athlete returned. Postoperative season 2 was defined as the one following the returning season. To standardize relative performance across the 4 sports after shoulder arthroscopy, the percentage change in performance compared with preoperative values was used.

\section{Statistical Analysis}

Categorical data were analyzed using the Fisher exact test. Continuous variables were compared across sports cohorts using a 2-tailed Student $t$ test for normally distributed data. In comparing pre- and postinjury performance, 2-tailed paired $t$ tests evaluated players against themselves. Kaplan-Meier survivorship plots were computed for RTP and retirement end points and log-rank tests compared the differences between survivorships. Statistical analysis was performed using RStudio, Version 1.1.442 (RStudio Inc., Boston, MA). An $\alpha$ value of .05 was used.

\section{Results}

A total of 207 athletes (NHL, $\mathrm{n}=37$; NFL, $\mathrm{n}=8$; NBA, $\mathrm{n}=46$ and MLB, $\mathrm{n}=116)$ who underwent shoulder arthroscopy between 1998 and 2016 were identified. Six-hundred two athletes were excluded $(\mathrm{NHL}, \mathrm{n}=110 ; \mathrm{NFL}, \mathrm{n}=61 ; \mathrm{NBA}, \mathrm{n}=80 ; \mathrm{MLB}$, $\mathrm{n}=351$ ) (Fig 1). Demographic differences among the athletes in different sports included significantly greater BMI (28.7) for NFL players $(P=.0122)$. In addition, injured NBA players had a significantly lower BMI

Table 2. Characteristics of Athletes Before Shoulder Arthroscopy

\begin{tabular}{llcr}
\hline & Mean BMI & Mean Age at Injury, y & Mean Playing Experience (Seasons) \\
\hline Overall & $26.3(20.0-33.0)$ & $28.0(20-41)$ & $5.5(1-20)$ \\
NHL & $27.2(24.7-30.0)$ & $27.7(20-37)$ & $6.4(1-15)$ \\
NFL & $28.7(26.6-32.9)^{*}$ & $28.3(23-36)$ & $7.4(1-11)$ \\
NBA & $24.7(21.4-30.2) \dagger$ & $25.5(20-34) \dagger$ & $4.2(1-11) \dagger$ \\
MLB & $26.4(20.0-33.0)$ & $29.1(22-41)$ & $5.7(1-20)$ \\
\hline
\end{tabular}

NOTE. All values are reported as mean (range).

BMI, body mass index; MLB, Major League Baseball; NBA, National Basketball Association; NFL, National Football League; NHL, National Hockey League.

*NFL was reported to have a greater average BMI than all other athletes $(P=.0122)$.

${ }^{\dagger} \mathrm{NBA}$ athletes lower than all other athletes $(P<.01)$. 
Table 3. Outcomes After Shoulder Arthroscopy

\begin{tabular}{lll}
\hline & Return to Play, d & Career, Seasons \\
\hline Overall & $306(111-1488)$ & $4.6(1-14)$ \\
NHL & $210(111-631)$ & $4.8(1-11)$ \\
NFL & $296(233-342)$ & $4.7(1-8)$ \\
NBA & $201(32-745)^{*}$ & $5.8(1-14))^{*}$ \\
MLB & $413(94-1488) \dagger$ & $3.7(1-12) \dagger$ \\
\hline
\end{tabular}

NOTE. All values are reported as mean (range).

MLB, Major League Baseball; NBA, National Basketball Association; NFL, National Football League; NHL, National Hockey League.

*NBA athletes take shorter time to return to play and have longer careers following injury, compared with other athletes $(P<.01)$.

${ }^{\dagger}$ MLB athletes take a longer time to return to play and have shorter careers following injury, compared with other athletes $(P<.001)$.

(24.7, $P=.0122)$, age at injury $(25.5$ years, $P<.01)$, and number of years playing professionally before injury (4.2 years, $P<.01$ ) (Table 2 ).

\section{RTP and Career Length After Shoulder Arthroscopy}

The average time to RTP after surgery was 306 days (Table 3). NBA players returned in significantly less time than all other sports (201 days; $P<.01$ ), whereas MLB players took longer on average to return (413 days; $P<.001)$. Career length after injury followed a similar trend. Average career length following shoulder arthroscopy for all athletes was 4.6 seasons, with NBA players having a significantly longer postinjury career than the other sports (5.8 years; $P<.01$ ), and MLB players having a significantly shorter postinjury career (3.7 years; $P<.001$ ). Kaplan-Meier analysis also revealed significant differences in survivorship (defined as RTP in Fig 2, and retirement in Fig 3) among all 4 sports; $\log$ rank $P<.0001$.

\section{Performance and Outcome After Shoulder Arthroscopy}

Performance was assessed both via percent of games played following injury (Fig 4), and the relative percent change in each performance metric for each of the four sports (Fig 5). The NFL and NBA saw no significant difference in number of games played pre- and postinjury. In the NFL, players 2 years out from surgery played in $93.8 \%$ of games and $88.4 \%$ in postinjury year 1. NBA players were relatively consistent, playing in $73.5 \%$ to $75 \%$ of games across all seasons. MLB data indicated that not only do players typically lose the rest of the current season as demonstrated by the low percentage of games played in the injury season $(35.5 \%)$, but they also lost a majority of the postoperative season $(26.4 \% ; P<.05)$ before returning to a greater, but still relatively low level of play in year $2(39.5 \%)$. NHL players played significantly less in postoperative season $2(60.2 \%)$ than the preoperative $(75.0 \%)$ or postoperative year $1(74.9 \%),(P<.05)$.

With regards to performance, NHL players performed worse in postoperative season $1(-67.6 \%, P$ $<.05)$, but slightly better in postoperative season 2 $(2.7 \%, P=.08)$. NBA players did significantly worse with regards to performance in postoperative season $1(-8.7 \%, P<.05)$. They continued to perform worse in postoperative season $2(-6.2 \%, P=.19)$; however, this did not reach significance. MLB players performed similarly in postoperative season 1 and 2 with no significant difference $(2.2 \%$, and $3.3 \%$ respectively). Lastly, NFL players showed improvement; however, there were not enough players to achieve significance in their improvement following surgery.

\section{Discussion}

This study found that MLB players demonstrated significantly lower rates of RTP compared with all other sports. MLB players also took a longer time to RTP and had shorter careers following injury compared with other athletes. Performance scores for MLB players decreased in the short -term after surgery but returned to preoperative level at postoperative season 2 . Conversely, NBA players RTP more quickly and have longer careers following shoulder arthroscopy compared with other professional athletes, contrary to
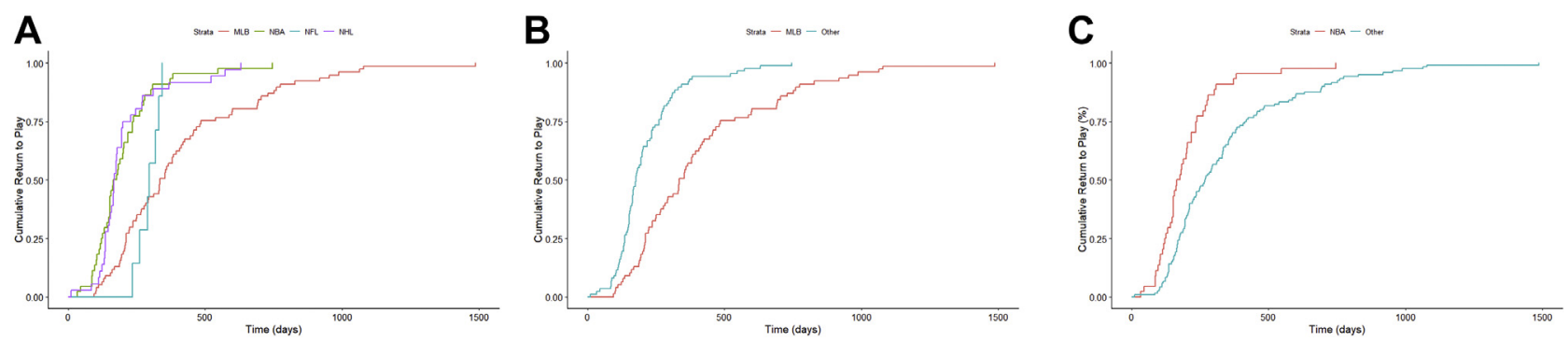

Fig 2. Time to return to play by sports. (A) Kaplan-Meier survival curve for time to return to play by sport showing a difference in the amount of time to return to play across all sports $(P<.0001)$. (B) MLB players had a survival for return to play that is slower when compared with all other sports $(P<.0001)$. (C) Survival for return to play for NBA players is faster compared with all other sports $(P<.0001)$. (MLB, Major League Baseball; NBA, National Basketball Association; NFL, National Football League; NHL, National Hockey League.) 

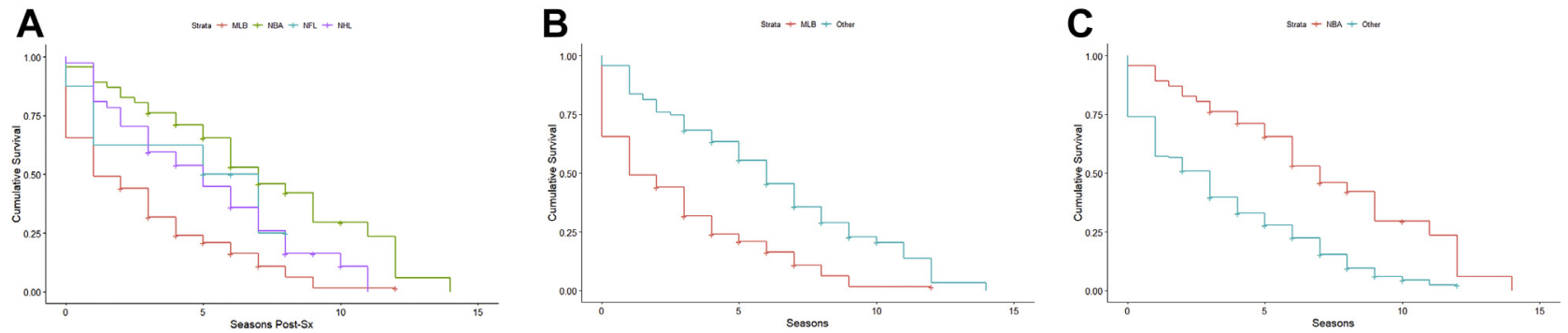

Fig 3. Career length (survival) following shoulder arthroscopy by Sports. Kaplan-Meier survival analysis of career length following arthroscopic shoulder surgery. (A) There was significant difference between length of career amongst the four major sports $(P<.0001)$. (B) Survival in terms of career length postarthroscopic shoulder surgery is greater in the NBA, compared with other sports $(P<.0001)$. (C) Survival in terms of career length until retirement postarthroscopic shoulder surgery is lower in the MLB, compared with other sports $(P<.0001)$. (MLB, Major League Baseball; NBA, National Basketball Association; NFL, National Football League; NHL, National Hockey League.)

our hypothesis. Performance scores for NBA players were worse in postoperative seasons 1 and 2. Players in the NFL and NBA saw no significant difference in the number of games played pre- and postshoulder arthroscopy, whereas MLB players typically lost the rest of the season and a majority of the postshoulder arthroscopy season.

Multiple factors likely contribute to these findings. Position played likely influences outcomes. Chalmers et al. $^{8}$ reported outcomes after shoulder surgery to treat pathologies including the labrum, capsule, rotator cuff, acromioclavicular joint, cartilage, biceps, and subacromial space among major league and minor league baseball players and found that most shoulder procedures were performed on pitchers (60\%, despite accounting for only $45 \%$ of all professional baseball players). Pitchers accounted for $66 \%(77 / 116)$ of our MLB cohort and may have contributed to the worse outcomes observed among MLB players, specifically the longest average time to RTP (413 days) and the shortest post-injury career length (3.7 years).

Our study found that performance scores in NHL players declined when comparing their preoperative season with their postoperative season 1 , and with a return to baseline in postoperative season 2. This finding contrasts with conclusions drawn by Rangavajjula et al., ${ }^{22}$ who evaluated 11 NHL players who underwent arthroscopic glenoid labral repair by one surgeon over a 5-year period. This study reported no significant decline in player performance at an average follow-up time of 19.4 months.

The divergence of physical demands imposed by baseball and basketball may explain the differences in postoperative outcomes for players in these 2 sports. When reviewing injuries to NBA players over a 17-year period, Drakos et al. ${ }^{23}$ reported that only 3.7\% $(466 / 12,594)$ of all injuries were shoulder injuries, whereas $62.4 \%(7853 / 12,594)$ of injuries involved the lower extremity. The relative differences in outcomes between these sports warrants further study to better understand the reasons for these findings.

\section{Limitations}

This study has several limitations. Without a comprehensive and consistent league database that tracks player injuries and treatments, it is possible that not all athletes were included in this review. Therefore, it was not possible to calculate incidence and prevalence with our study design. Second, the details of the surgical technique were not available for all players, so we were unable to compare surgical techniques. Heterogeneity of the surgeons and surgeons' skill also present limitations.

Selection bias may have led to a greater percentage of well-known, more popular athletes being included as opposed to backup players. In addition, the rehabilitation program used postoperatively was unavailable. Other limitations include the absence of career length for players still playing in their respective leagues. Moreover, there are many reasons unrelated to

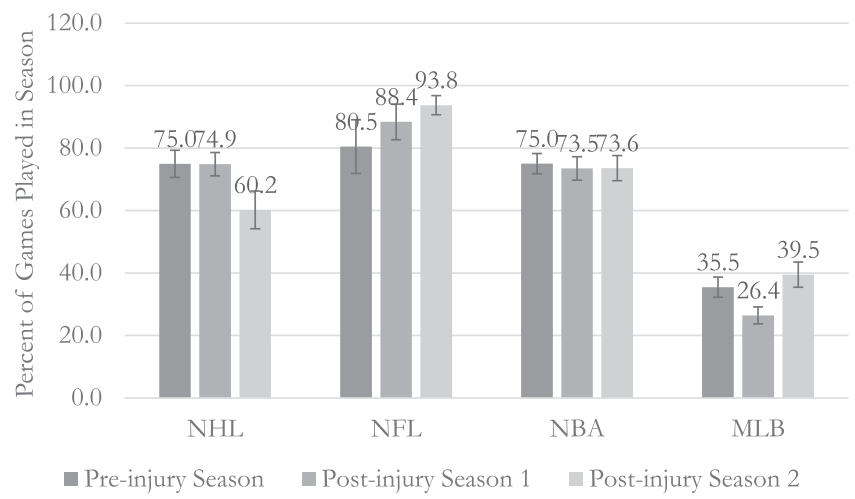

Fig 4. Percent of games played preinjury and in year 1 and 2 postinjury. Percent of games played across sports comparing the season before surgery, postoperative season 1, and postoperative season 2. (MLB, Major League Baseball; NBA, National Basketball Association; NFL, National Football League; NHL, National Hockey League.) 


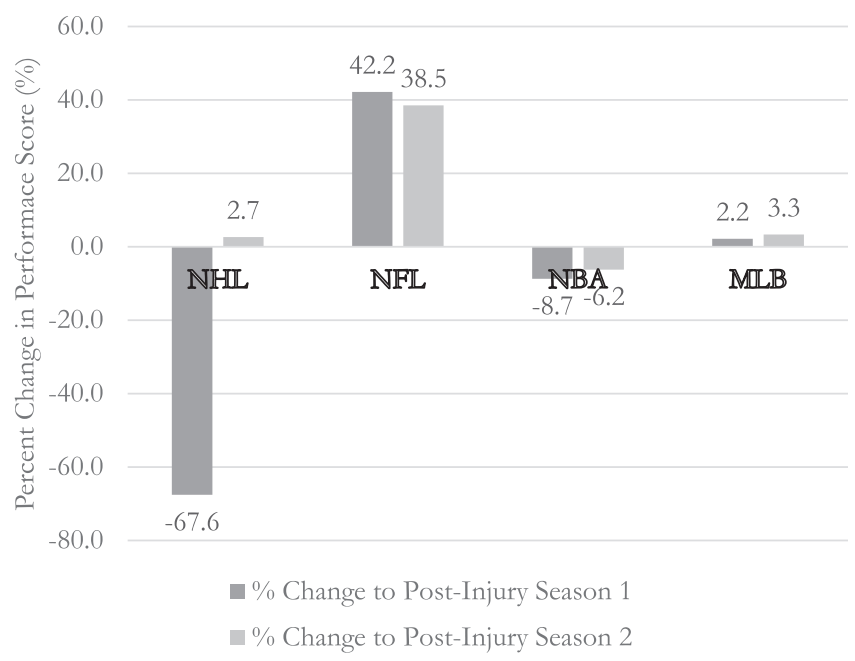

Fig 5. Percent change in performance by sport in year 1 and 2 postinjury. Percent change in performance scores across sports comparing the season before surgery with postoperative season 1 and postoperative season 2. (MLB, Major League Baseball; NBA, National Basketball Association; NFL, National Football League; NHL, National Hockey League.)

performance that may influence an athlete's decision to retire (e.g., contract negotiations, personal factors, age, experience) that were not accounted for because of limitations in the information available. As in any sport, factors outside of the players' control, such as roster changes or coaching, may have affected playing time and performance. For the purposes of this study, the first game on an active roster defined successful RTP, but it is important to consider that this may not define the exact length of recovery. Medical clearance to RTP may predate returning to the field if during the offseason.

Our NFL cohort was a small sample size despite reviewing 19 seasons of injury data in the NFL. Athletes included in this study underwent shoulder arthroscopy; however, it was not possible to obtain information about the specific diagnoses or procedures performed for all of these patients. We acknowledge that the variation in shoulder pathology and procedure(s) performed may affect outcomes. In addition, all the participants in this study were male.

\section{Conclusions}

There is a modest RTP rate among professional athletes following shoulder arthroscopy. MLB players have the longest average time to RTP and the shortest postinjury careers following shoulder arthroscopy. However, they demonstrate no significant decline in their performance score following their injury. Conversely, NBA players had the shortest average time to RTP and the longest postinjury career. Both NBA and NHL athletes experienced a decrease in performance in their first postoperative season.

\section{References}

1. DeHaven KE, Lintner DM. Athletic injuries: Comparison by age, sport, and gender. Am J Sports Me 1986;14: 218-224.

2. Farmer KW, Wright TW. Shoulder arthroscopy: The basics. J Hand Surg 2015;40:817-821.

3. Lawrence DW, Hutchison MG, Comper P. Descriptive epidemiology of musculoskeletal injuries and concussions in the National Football League, 2012-2014. Orthop J Sports Med 2015;3:232596711558365.

4. Piper CC, Hughes AJ, Ma Y, Wang H, Neviaser AS. Operative versus nonoperative treatment for the management of full-thickness rotator cuff tears: A systematic review and meta-analysis. J Shoulder Elbow Surg 2018;27: 572-576.

5. Kitayama S, Sugaya H, Takahashi N, et al. Clinical outcome and glenoid morphology after arthroscopic repair of chronic osseous Bankart lesions: A five to eightyear follow-up study. J Bone Joint Surg 2015;97: 1833-1843.

6. Weber AE, Kontaxis A, O'Brien SJ, Bedi A. The biomechanics of throwing: Simplified and cogent. Sports Med Arthrosc Rev 2014;22:72-79.

7. Park J-Y, Lee J-H, Oh K-S, Chung SW, Lim J, Noh YM. Return to play after arthroscopic treatment for shoulder instability in elite and professional baseball players. J Shoulder Elbow Surg 2019;28:77-81.

8. Chalmers PN, Erickson BJ, D’Angelo J, Ma K, Romeo AA. Epidemiology of shoulder surgery among professional baseball players. Am J Sports Med 2019;47: 1068-1073.

9. Robins RJ, Daruwalla JH, Gamradt SC, et al. Return to play after shoulder instability surgery in National Collegiate Athletic Association Division I intercollegiate football athletes. Am J Sports Med 2017;45: 2329-2335.

10. Namdari S, Baldwin K, Ahn A, Huffman GR, Sennett BJ. Performance after rotator cuff tear and operative treatment: A case-control study of Major League Baseball pitchers. J Athl Train 201 1;46:296-302.

11. Okoroha KR, Taylor KA, Marshall NE, et al. Return to play after shoulder instability in National Football League athletes. J Shoulder Elbow Surg 2018;27:17-22.

12. Lu Y, Okoroha KR, Patel BH, et al. Return to play and performance after shoulder instability in National Basketball Association athletes. J Shoulder Elbow Surg 2020;29:50-57.

13. Abdul-Rassoul H, Galvin JW, Curry EJ, Simon J, Li X. Return to sport after surgical treatment for anterior shoulder instability: A systematic review. Am J Sports Med 2019;47:1507-1515.

14. Amin NH, Old AB, Tabb LP, Garg R, Toossi N, Cerynik DL. Performance outcomes after repair of complete Achilles tendon ruptures in National Basketball Association players. Am J Sports Med 2013;41:1864-1868.

15. Schroeder GD, McCarthy KJ, Micev AJ, Terry MA, Hsu WK. Performance-based outcomes after nonoperative treatment, discectomy, and/or fusion for a lumbar disc herniation in National Hockey League athletes. Am J Sports Med 2013;41:2604-2608. 
16. Mai HT, Chun DS, Schneider AD, et al. Performancebased outcomes after anterior cruciate ligament reconstruction in professional athletes differ between sports. Am J Sports Med 2017;45:2226-2232.

17. Erickson BJ, Harris JD, Cole BJ, et al. Performance and return to sport after anterior cruciate ligament reconstruction in National Hockey League players. Orthop J Sports Med 2014;2:232596711454883.

18. Harris JD, Erickson BJ, Bach BR, et al. Return-to-sport and performance after anterior cruciate ligament reconstruction in National Basketball Association players. Sports Health 2013;5:562-568.

19. Hsu WK. Performance-based outcomes following lumbar discectomy in professional athletes in the National Football league. Spine (Phila Pa 1976) 2010;35:1247-1251.
20. Shah VM, Andrews JR, Fleisig GS, McMichael CS, Lemak LJ. Return to play after anterior cruciate ligament reconstruction in National Football League athletes. Am J Sports Med 2010;38:2233-2239.

21. Christian RA, Lubbe RJ, Chun DS, Selley RS, Terry MA, Hsu WK. Prognosis following hip arthroscopy varies in professional athletes based on sport. Arthroscopy 2019;35: 837-842.el.

22. Rangavajjula A, Hyatt A, Raneses E, McCrossin J, Cohen S, DeLuca P. Return to play after treatment of shoulder labral tears in professional hockey players. Phys Sportsmed 2016;44:119-125.

23. Drakos MC, Domb B, Starkey C, Callahan L, Allen AA. Injury in the National Basketball Association: A 17-year overview. Sports Health 2010;2:284-290. 